(c) The Author(s), 2021. Published by Cambridge University Press on behalf of The Nutrition Society. This is an Open Access article, distributed under the terms of the Creative Commons Attribution licence (http://creativecommons.org/licenses/by/4.0/), which permits unrestricted re-use, distribution, and reproduction in any medium, provided the original work is properly cited.

\title{
The nutritional impact of replacing dietary meat with meat alternatives in the UK: a modelling analysis using nationally representative data
}

\author{
Dominic N. Farsi*, Dinithi Uthumange, Jose Munoz Munoz and Daniel M. Commane \\ Department of Applied Sciences, Northumbria University, Newcastle upon Tyne, NE1 8ST, UK \\ (Submitted 6 May 2021 - Final revision received 5 July 2021 - Accepted 14 July 2021 - First published online 21 July 2021)
}

\section{Abstract}

Dietary patterns high in meat compromise both planetary and human health. Meat alternatives may help to facilitate meat reduction; however, the nutritional implications of displacing meat with meat alternatives does not appear to have been evaluated. Here, the ninth cycle of the National Diet and Nutrition Survey was used as the basis of models to assess the effect of meat substitution on nutritional intake. We implemented three models; model 1 replaced $25 \%, 50 \%, 75 \%$ or $100 \%$ of the current meat intake with a weighted mean of meat alternatives within the UK market. Model 2 compared different ingredient categories of meat alternative; vegetable, mycoprotein, a combination of bean and pea, tofu, nut and soya. Model 3 compared fortified $v$. unfortified meat alternatives. The models elicited significant shifts in nutrients. Overall, carbohydrate, fibre, sugars and $\mathrm{Na}$ increased, whereas reductions were found for protein, total and saturated fat, $\mathrm{Fe}$ and $\mathrm{B}_{12}$. Greatest effects were seen for vegetable-based $(+24 \cdot 63 \mathrm{~g} / \mathrm{d}$ carbohydrates), mycoprotein-based $(-6 \cdot 12 \mathrm{~g} / \mathrm{d}$ total fat), nut-based $(-19 \cdot 79 \mathrm{~g} / \mathrm{d}$ protein, $+10 \cdot 23 \mathrm{~g} / \mathrm{d}$ fibre; $-4 \cdot 80 \mathrm{~g} / \mathrm{d}$ saturated fat, $+7 \cdot 44 \mathrm{~g} / \mathrm{d}$ sugars $)$, soya-based $(+495.98 \mathrm{mg} / \mathrm{d} \mathrm{Na})$ and tofu-based $\left(+7 \cdot 63 \mathrm{mg} / \mathrm{d} \mathrm{Fe},-2 \cdot 02 \mu \mathrm{g} / \mathrm{d} \mathrm{B} \mathrm{B}_{12}\right)$. Our results suggest that meat alternatives can be a healthful replacement for meat if chosen correctly. Consumers should choose meat alternatives low in Na and sugar, high in fibre, protein and with high micronutrient density, to avoid compromising nutritional intake if reducing meat intake. Manufacturers and policy makers should consider fortification of meat alternatives with nutrients such as Fe and $\mathrm{B}_{12}$ and focus on reducing Na and sugar content.

Keywords: Meat replacement: meat alternatives: Nutritional intake: Nutritional requirements: Public health

Globally, annual per capita meat consumption has increased by $20 \mathrm{~kg}$ since $1961^{(1)}$. This sector of our food system contributes substantially to greenhouse gas emissions ${ }^{(2)}$, depletes natural resources $^{(3-5)}$ and compromises animal welfare. In the UK, meat can be a valuable source of nutrients; however, overconsumption is associated with an increased risk of CVD, type 2 diabetes ${ }^{(6-8)}$ and cancer $^{(9-16)}$. Reducing meat consumption may therefore promote human health, protect animal welfare and benefit the environment.

Changing dietary behaviours to elicit a transition towards alternative protein sources is challenging in part owing to strongly held taste preferences, culinary traditions and social and cultural norms ${ }^{(17)}$. Meat alternatives, resembling meat in appearance, preparation and eating experience, could therefore play an important role in enabling dietary change ${ }^{(18)}$. Integration of meat alternatives into the diet is subtle and does not require an overhaul of food consumption and meal patterns ${ }^{(19-21)}$. Although meat alternatives have been available for years, their popularity with consumers has increased rapidly in recent times; due in part to producers better simulating the taste, texture and functionality of traditional meat products. There has also been an increase in the direction of marketing towards meat-eating consumers, rather than just vegans and vegetarians ${ }^{(22)}$.

The rapid increase in the consumption of meat alternatives has raised concerns regarding their overall healthfulness and the potential displacement of valuable nutrients. The developing meat alternative market includes an array of food products with variable nutritional quality, some of which might be considered ultra-processed ${ }^{(23)}$. If these foods are to play a role in reducing meat consumption at a population level, it is essential that any population level nutritional benefits and consequences are identified early and actions taken to mitigate undesirable effects.

Here, we model the potential nutritional implications of meat replacement by using the ninth cycle (years 2016-2017) of the nationally representative UK National Diet and Nutrition Survey rolling program (NDNS RP). We present the nutritional implications of complete and partial meat substitution, using models that either assume replacement of meat with a range of alternative products, based on current UK purchasing data, or models that assume replacement of meat with specific meat alternative ingredient categories. To our understanding, this is 
the first study to evaluate the nutritional implications of such dietary-replacement scenarios.

\section{Methods}

\section{Study population}

Dietary intake data for the UK population were drawn from the ninth cycle of the NDNS RP. The NDNS RP is a Public Health England and Food Standards Agency funded survey of the food consumption, nutrient intake and nutritional status of people aged 1.5 years and older living in private households in the UK and is representative of the UK population ${ }^{(24)}$. Detailed descriptions of the NDNS RP survey design and sampling methods can be found elsewhere ${ }^{(25-27)}$. The 2016-2017 survey cycle year used in the present modelling analysis included 1253 participants aged $1.5-95$ years.

\section{Dietary records}

The NDNS RP collected habitual dietary data using 4-d estimated food diaries ${ }^{(24-26)}$. Data from food diaries have been aggregated for each respondent to provide publicly available daily averages of self-reported food and nutrient intake. For this analysis, we excluded data sets for participants with extreme reported energy intakes ( $<2092 \mathrm{~kJ}->20920 \mathrm{~kJ}$ ). Data sets from subjects who selfreported abstaining from meat, or with dietary data devoid of any meat, were also excluded. A common occurrence in the collection of habitual dietary intake data is underreporting of energy intake ${ }^{(28)}$, which the NDNS RP data drawn upon here corroborates. There are different methods to approach underreporting $^{(29)}$; in the present analysis, we adjusted nutrients to age and gender-specific estimated average requirements for energy.

Sub-analyses were performed by stratifying by sex and age group, using the same stratification system as the NDNS RP (male and female; 4-10 years, 11-18 years and 19-64 years, over 65 years). Children in 1.5-3 years subgroups were not included as nutrient requirements are specific for each age in this subpopulation. In addition, dietary patterns at this stage in life may not include substantial amounts of solid food such as meat. This left a total of 1110 respondents for inclusion in the analysis.

\section{Self-reported nutritional intake from meat}

The current level of meat consumption in the UK was estimated from the NDNS data set. Briefly, the NDNS RP reports meat intake in grams per day broken down by type (i.e. 'beef, lamb, pork, offal etc'), We allocated these categories into food type groups; 'red meat; 'processed red meat', 'white meat', 'processed white meat' and 'seafood'. In this analysis seafood was included with meat as a source of animal flesh. We note that the UK dietary guidelines encourage a population level increase in fish consumption as a source of omega 3 fatty acids and other nutrients, however, most UK vegetarians describe themselves as lactoovo-vegetarian or vegan, and only a minority describe themselves as pescatarian.

The allocation and stratification of animal meat within the NDNS data set is described in Table 1.
The total nutritional contribution of meat to the UK diet was estimated by combining the intake data with the nutritional composition data from the McCance and Widdowson composition of food tables ${ }^{(30)}$. Briefly, an aggregate quantity of nutrient, per gram, for each of the meat subtypes was multiplied by the intake in grams per day, for each respondent. The totality of these nutrition scores by subtype was then used to estimate the total nutritional value of meat products to the diet for each individual respondent.

\section{Nutritional content of meat alternatives}

Products were identified through product searches on UK supermarket websites using the key words, 'meat alternatives', 'meat substitutes', 'meat-free', 'plant-based', 'vegan' and 'vegetarian', to ensure a wide capture of meat alternative products. Following data collection, the products that met these criteria were grouped into ingredient categories (Supplementary Table S1).

The nutritional profile of meat alternatives was calculated based on product labels, information from supermarket and manufacturer websites, as well as searching nutrition databases for products. Where nutrient data was not available for a product, manufacturers were contacted to request further details. This data was used to estimate the aggregate nutritional composition per gram for each of the meat alternative ingredient categories, based on the mean nutritional composition of the individual products included in each respective category.

There was incomplete availability of nutritional data across the product categories for many of the micronutrients including I, Zn, and Se. There was available nutritional data for the following nutrients: carbohydrate, protein, total fat, saturated fat, fibre, sugar, $\mathrm{Na}, \mathrm{Fe}$ and $\mathrm{B}_{12}$. We deemed the data on these nutrients of good quality for inclusion in subsequent analysis

\section{Meat-replacement scenarios}

Here, we assessed the nutritional implications of a set of scenarios for the widespread replacement of meat with meat alternatives in the UK population (Table 2).

Model 1: the effect of meat reduction and replacement with meat alternatives. In the first replacement model, we generated a weighted mean of the nutritional quality of meat alternatives based on the current market share for meat alternative products in the UK; vegetable $23 \%$, mycoprotein $18 \%$, bean $17 \%$, soya $15 \%$, nut $14 \%$ and tofu $13 \%{ }^{(31)}$.

We then looked at the effect of progressively reducing the amount of meat in each respondent's diet by $25 \%$ (MA-25), $50 \%$ (MA-50), $75 \%$ (MA-75) and $100 \%$ (MA-100) and replacing the removed nutrients with the weighted nutritional score of the meat alternatives on a per weight basis (Table 2).

Model 2: a comparison of the effects of replacing nutrients from meat across specific ingredient categories of meat alternative. In a second model, we compared the nutritional impact of replacing meat with meat alternatives produced from a particular category of ingredient. Specifically, we replaced the total amount of meat in each individual respondent's diet with 
Table 1. NDNS food groups used to calculate self-reported meat intake

\begin{tabular}{|c|c|c|c|}
\hline & Meat subtype & NDNS category* & Description of category \\
\hline Total Meat & $\begin{array}{l}\text { Processed red meat } \\
\text { White meat } \\
\text { Processed white meat } \\
\text { Seafood }\end{array}$ & $\begin{array}{l}\text { "beefg" } \\
\text { "lambg" } \\
\text { "porkg" } \\
\text { "offalg" } \\
\text { "liverdishes" } \\
\text { "otherredmeatg" } \\
\text { "burgersg" } \\
\text { "sausagesg" } \\
\text { "baconandham" } \\
\text { "burgersandkebabs" } \\
\text { "processedredmeatg" } \\
\text { "poultryg" } \\
\text { "gamebirdsg" } \\
\text { "coatedchicken" } \\
\text { "processedpoultryg" } \\
\text { "whitefishg" } \\
\text { "oilyfishg" } \\
\text { "cannedtunag" } \\
\text { "shellfishg" } \\
\text { "whitefishcoatedorfried" }\end{array}$ & $\begin{array}{l}\text { Amount of beef consumed }(\mathrm{g}) \\
\text { Amount of lamb consumed }(\mathrm{g}) \\
\text { Amount of pork consumed }(\mathrm{g}) \\
\text { Amount of offal consumed }(\mathrm{g}) \\
\text { Amount of liver consumed }(\mathrm{g}) \\
\text { Amount of other red meat consumed }(\mathrm{g}) \\
\text { Amount of burger consumed }(\mathrm{g}) \\
\text { Amount of sausages consumed }(\mathrm{g}) \\
\text { Amount of bacon and/or ham consumed }(\mathrm{g}) \\
\text { Amount of burger and/or kebab consumed }(\mathrm{g}) \\
\text { Amount of other processed red meat consumed }(\mathrm{g}) \\
\text { Amount of poultry consumed }(\mathrm{g}) \\
\text { Amount of game consumed }(\mathrm{g}) \\
\text { Amount of coated chicken products consumed }(\mathrm{g}) \\
\text { Amount of processed poultry consumed }(\mathrm{g}) \\
\text { Amount of white fish consumed }(\mathrm{g}) \\
\text { Amount of oily fish consumed }(\mathrm{g}) \\
\text { Amount of canned tuna consumed }(\mathrm{g}) \\
\text { Amount of shellfish consumed }(\mathrm{g}) \\
\text { Amount of white fish (coated or fried) consumed }(\mathrm{g})\end{array}$ \\
\hline
\end{tabular}

* As displayed in NDNS data set.

Table 2. Meat-replacement models implemented in the present modelling analysis

\begin{tabular}{|c|c|c|}
\hline \multicolumn{2}{|c|}{ Replacement Scenario Models } & \multirow{2}{*}{$\begin{array}{l}\text { Description of model } \\
\text { Partial replacement substituting } 25 \% \text { of the current self-reported meat intake with a composite of meat alternatives. }\end{array}$} \\
\hline /e & MA-25 & \\
\hline & MA-50 & Partial replacement substituting $50 \%$ of the current self-reported meat intake with a composite of meat alternatives. \\
\hline & MA-75 & Partial replacement substituting $75 \%$ of the current self-reported meat intake with a composite of meat alternatives. \\
\hline & MA-100 & Full replacement substituting $100^{\circ}$ \\
\hline \multirow[t]{6}{*}{$\begin{array}{l}\text { Ingredient } \\
\text { (Model 2) }\end{array}$} & Vegetable & $\begin{array}{l}\text { Full replacement substituting } 100 \% \text { of the current self-reported meat intake with meat alternatives produced predomi- } \\
\text { nantly from vegetables. }\end{array}$ \\
\hline & Mycoprotein & $\begin{array}{l}\text { Full replacement substituting } 100 \% \text { of the current self-reported meat intake with meat alternatives produced predomi- } \\
\text { nantly from mycoprotein. }\end{array}$ \\
\hline & Legume & $\begin{array}{l}\text { Full replacement substituting } 100 \% \text { of the current self-reported meat intake with meat alternatives produced predomi- } \\
\text { nantly from bean and pea. }\end{array}$ \\
\hline & Tofu & Full replacement substituting $100 \%$ of the current self-reported meat intake with meat alternatives produced from tofu. \\
\hline & Nut & $\begin{array}{l}\text { Full replacement substituting } 100 \% \text { of the current self-reported meat intake with meat alternatives produced predomi- } \\
\text { nantly from nut. }\end{array}$ \\
\hline & Soya & $\begin{array}{l}\text { Full replacement substituting } 100 \% \text { of the current self-reported meat intake with meat alternatives produced predomi- } \\
\text { nantly from soya. }\end{array}$ \\
\hline \multirow[t]{2}{*}{$\begin{array}{l}\text { Fortification } \\
\quad(\text { Model 3) * }\end{array}$} & Fortified & $\begin{array}{l}\text { Full replacement substituting } 100 \% \text { of the current self-reported meat intake with meat alternatives that have been for- } \\
\text { tified with nutrients. }\end{array}$ \\
\hline & Unfortified & $\begin{array}{l}\text { Full replacement substituting } 100 \% \text { of the current self-reported meat intake with meat alternatives that have not been } \\
\text { fortified with nutrients. }\end{array}$ \\
\hline
\end{tabular}

*Products identified as fortified if 1 ) explicitly stated nutrient fortification had been applied during manufacturing process; 2) isolated nutrients included in ingredient list. Products not meeting 1) or 2) identified as unfortified.

vegetable-based (Vegetable), mycoprotein-based (Mycoprotein), a combination of bean and pea-based (Legume), tofu-based (Tofu), nut-based (Nut) and soya-based (Soya) meat alternatives (Table 2).

Model 3: substitution with fortified v. unfortified meat alternatives. Within the food products identified, $14 \%$ were fortified with either $\mathrm{Fe}, \mathrm{B}_{12}$, or both. Taking this into account, in a third and final model, we compared the effects of replacing the total amount of meat in each person's diet with either fortified meat alternatives (Fortified) or unfortified meat alternatives (Unfortified) (Table 2).
We implemented each replacement strategy by removing the nutrient contribution of meat from each individual respondents' total nutritional intake, followed by replacing this with the nutritional data for the equivalent weight of meat alternatives. We adjusted the final total nutritional intake after substitution to match the energy content of each participant's diet.

\section{Comparators and subjective model corrections}

Due to the variable quality of available nutritional data and the relevance to public health, we have elected in this analysis to focus on the macronutrients, protein, fat and carbohydrate, as well as saturated fat, total sugars and $\mathrm{Na}$ due to public health 
guidance to limit their intake ${ }^{(32,33)}$. In addition, fibre was selected as authoritative bodies advise an intake of $30 \mathrm{~g} / \mathrm{d}$ for the adult population $^{(33)}$; which many fail to achieve ${ }^{(34)}$. We hypothesised that fibre would increase in the replacement models as a result of the higher fibre content of meat alternatives compared with meat ${ }^{(35)}$. We also assessed influences on $\mathrm{Fe}$ and $\mathrm{B}_{12}$, as the intake of these nutrients may be inadequate when transitioning to a dietary pattern devoid of animal based foods ${ }^{(36)}$.

We analysed the nutritional adequacy of the meat-replacement models by comparing the nutrient values to the dietary reference values (DRV) for Food Energy and Nutrients for the $\mathrm{UK}^{(32,33,37)}$. DRV comprise a series of estimates of the amount of energy and nutrients needed by different groups of healthy people in the UK population. In accordance with the DRV, we used the estimated average requirements as a comparator for total energy, whereas for protein, $\mathrm{Na}, \mathrm{Fe}$ and $\mathrm{B}_{12}$, the reference nutrient intakes (RNI) were used. For fat and carbohydrates (including total sugars, saturated fat and fibre), we used the UK DRV which for total fat (35\%), saturated fat (11\%) and total carbohydrates (50\%) are given as a percentage of daily energy intake ${ }^{(32,33,37)}$. The current recommendations for protein is to intake $0.75 \mathrm{~g} / \mathrm{kg}$ bodyweight ${ }^{(33,37)}$, as the data set in the current analysis contains a diverse age range which will also comprise different body types, a protein target of making up the remaining $15 \%$ of total energy intake after the contributions of fat $(35 \%)$ and carbohydrates (50\%) was employed instead.

Since the recommendations differ by age and sex, we calculated the average values for nutrients across the population subgroups (male and female; 4-10 years, 11-18 years, 19-64 years and over 65 years). We also incorporated a group that represented the total number of participants (both male and female, ages 4 years and above) and averaged all DRV categories to obtain a population average. This group would act as the representative of the UK population and used in the main analysis.

\section{Statistical analysis}

Differences in nutrient intake between the meat-replacement models and the current intake were compared using linear models with nutrients as the dependent variable and the replacement models as the independent variable, using the current intake as the reference. The differences in nutrient intake between all scenarios (current and replacement models) with reference to DRV were then compared using linear models in the same manner but including the current intake with the replacement models as the independent variable and then using DRV used as the reference. To assess the nutrient intake between meat-replacement models, an ANOVA was implemented, using an $\alpha=0.05$, followed by a post hoc Tukey test to determine the significance of differences between models. All analyses were performed using R statistical software (version 4.0.0) ${ }^{(38)}$.

\section{Results}

\section{Self-reported meat intake}

The average self-reported intake of both total meat and meat subgroup for the total population, as well separate population subgroups, is shown in Table 3. For the total population, the self-reported average meat intake was $132.25 \mathrm{~g} / \mathrm{d}$ (95\% CI, $128.02-136.48 \mathrm{~g} / \mathrm{d}$ ). Processed meat was the largest contributor to total meat intake $(35.98 \%)$, followed by white meat (27.22), red meat (19.44\%) and seafood (13.36\%), with processed white meat contributing the lowest (3.99\%). Males aged 19-64 years consumed the greatest amount of meat (mean, $177.55 \mathrm{~g} / \mathrm{d}$; 95\% CI, 165.33-189.77 g/d), while girls aged 4-10 years consumed the least amount of meat (mean, $98.75 \mathrm{~g} / \mathrm{d}$; $95 \% \mathrm{CI}$, $91 \cdot 28-106 \cdot 23 \mathrm{~g} / \mathrm{d})$.

\section{Projected changes in nutritional intake}

Overall, the implemented meat-replacement scenarios elicited many differences in the nutritional intake. The current nutrient intake for the total population and for each replacement model (MA-25, MA-50, MA-75, MA-100, Vegetable, Mycoprotein, Legume, Tofu, Nut, Soya, Fortified, Unfortified) is included in Table 4, while the projected differences for each replacement model in comparison to the current intake are included in Table 5.

Model 1: the effect of meat reduction and replacement with meat alternatives. In model 1 , we explored projected changes in nutritional intake given a graded replacement of meat from replacing $25 \%$ of current meat intake, through to a $100 \%$ replacement, using weighted composite nutritional values for the meat alternatives based on consumer purchasing data. We observed a linear increase in total carbohydrate consumption with the decrease in meat, reaching an additional $19 \mathrm{~g} / \mathrm{d}$ in a $100 \%$ meat-replacement scenario. This increase in projected carbohydrates was statistically significant in all scenarios except the $25 \%$ replacement model (MA-50, $P=0 \cdot 018$; MA-75, $P \leq 0 \cdot 001$; MA-100, $P<0.001)$. Importantly, the projected increased intake of carbohydrates was only associated with a small linear increase in projected sugar intake; this increase did not reach statistical significance until $100 \%$ of current meat was replaced $(+04 \cdot 16$ $\mathrm{g} / \mathrm{d}, P=0.05)$. In contrast, with decreasing consumption of meat and increasing consumption of meat alternatives, there was a graded decrease in projected total protein intake (MA-25, $-3.40 \mathrm{~g} / \mathrm{d}, P=0.002 ;$ MA-50, $-6.99 \mathrm{~g} / \mathrm{d}, P \leq 0.001 ;$ MA-75, $-10.77 \mathrm{~g} / \mathrm{d}, P \leq 0.001 ;$ MA-100, $-14.77 \mathrm{~g} / \mathrm{d}, P<0.001)$. There was also a linear decrease in the intake of fat and importantly, of saturated fat, with decreasing meat and increasing meat alternative intake. The decrease in saturated fat with complete meat substitution was equivalent to $3.96 \mathrm{~g} / \mathrm{d}(P<0.001)$.

Total fibre intake was increased significantly under each meat-replacement scenario. A $100 \%$ replacement of meat with meat alternatives was associated with an $8.15 \mathrm{~g}$ increase in total daily fibre intake $(P<0 \cdot 001)$. Notably, there was also a linear increase in $\mathrm{Na}$ intake, with a total replacement of meat being associated with a projected $228.03 \mathrm{mg}$ increase in Na per day $(P<0 \cdot 001)$. There were non-statistically significant decreases in projected intake of both $\mathrm{Fe}$ and of vitamin $\mathrm{B}_{12}$.

Similar effects were found in sub analyses across each of the population subgroups (Supplementary Tables S3-S18). 
Table 3. Self-Reported meat intake (total meat and meat subtype) stratified by age and gender (Mean values and $95 \%$ confidence intervals)

\begin{tabular}{|c|c|c|c|c|c|c|c|c|c|c|c|c|c|c|c|c|c|c|c|c|c|c|}
\hline \multirow[t]{2}{*}{ Subgroup } & \multirow[b]{2}{*}{ Mean } & \multirow{2}{*}{$\begin{array}{c}\begin{array}{c}\text { Total meat, } \\
\mathrm{g} / \mathrm{d}\end{array} \\
95 \% \mathrm{Cl}\end{array}$} & \multirow[b]{2}{*}{ Mean } & \multirow{2}{*}{$\begin{array}{l}\begin{array}{c}\text { Red meat, } \\
\mathrm{g} / \mathrm{da}\end{array} \\
95 \% \mathrm{Cl}\end{array}$} & \multirow[b]{2}{*}{ Mean } & \multirow{2}{*}{$\begin{array}{c}\text { Contribution } \\
\text { to total meat, } \\
\% \\
95 \% \mathrm{Cl}\end{array}$} & \multirow[b]{2}{*}{ Mean } & \multirow{2}{*}{$\begin{array}{c}\begin{array}{c}\text { Processed } \\
\text { meat, g/d }\end{array} \\
95 \% \mathrm{Cl}\end{array}$} & \multirow[b]{2}{*}{ Mean } & \multirow{2}{*}{$\begin{array}{c}\text { Contribution } \\
\text { to total meat, } \\
\% \\
95 \% \mathrm{Cl}\end{array}$} & \multirow[b]{2}{*}{ Mean } & \multirow{2}{*}{$\begin{array}{l}\text { White meat, } \\
\mathrm{g} / \mathrm{d} \\
95 \% \mathrm{Cl}\end{array}$} & \multirow[b]{2}{*}{ Mean } & \multirow{2}{*}{$\begin{array}{c}\text { Contribution } \\
\text { to total meat, } \\
\% \\
95 \% \mathrm{Cl}\end{array}$} & \multirow[b]{2}{*}{ Mean } & \multirow{2}{*}{$\begin{array}{c}\text { Processed } \\
\text { white meat, } \\
\mathrm{g} / \mathrm{d} \\
95 \% \mathrm{Cl}\end{array}$} & \multirow[b]{2}{*}{ Mean } & \multirow{2}{*}{$\begin{array}{c}\text { Contribution } \\
\text { to total meat, } \\
\% \\
95 \% \mathrm{Cl}\end{array}$} & \multirow[b]{2}{*}{ Mean } & \multirow{2}{*}{$\begin{array}{c}\begin{array}{c}\text { Seafood, g/ } \\
\text { d }\end{array} \\
95 \% \mathrm{Cl}\end{array}$} & \multicolumn{2}{|c|}{$\begin{array}{l}\text { Contribution to total } \\
\text { meat, \% }\end{array}$} \\
\hline & & & & & & & & & & & & & & & & & & & & & Mean & $95 \% \mathrm{Cl}$ \\
\hline Male, 4- 10years & 106.01 & $96.61,115.42$ & 14.76 & $11.74,17.77$ & 13.92 & $12 \cdot 16,15 \cdot 39$ & 47.66 & $41 \cdot 19,54 \cdot 13$ & 44.95 & $42 \cdot 63,46 \cdot 89$ & 26.27 & $22 \cdot 30,30 \cdot 24$ & 24.78 & $23 \cdot 08,26 \cdot 20$ & 6.41 & $4.88,7.95$ & 6.05 & $5.05,6.89$ & 10.92 & $8.64,13.20$ & $10 \cdot 30$ & $8.95,11 \cdot 4$ \\
\hline Female, 4 - 10years & 98.75 & $91 \cdot 28,106 \cdot 23$ & 13.72 & $10 \cdot 92,16.51$ & 13.89 & $11.97,15.54$ & 40.97 & $34 \cdot 84,47 \cdot 11$ & 41.49 & $38 \cdot 17,44 \cdot 35$ & 24.47 & $20.88,28.07$ & 24.78 & $22 \cdot 87,26 \cdot 42$ & 6.88 & $5.26,8.49$ & 6.96 & $5.77,7.99$ & 12.71 & $10 \cdot 20,15 \cdot 22$ & 12.87 & $11 \cdot 18,14 \cdot 33$ \\
\hline Male, $11-18$ years & 146.71 & $134 \cdot 32,159 \cdot 10$ & $21 \cdot 4$ & $16 \cdot 47,26 \cdot 32$ & 14.59 & $12 \cdot 26,16 \cdot 54$ & 60.37 & $50.55,70 \cdot 18$ & 41.15 & $37.63,44 \cdot 11$ & 40.79 & $33.57,48.01$ & 27.8 & $24 \cdot 99,30 \cdot 17$ & 9.14 & $5.71,12.57$ & 6.23 & $4 \cdot 25,7 \cdot 90$ & 15.01 & $10.57,19.46$ & $10 \cdot 23$ & $7 \cdot 87,12$ \\
\hline Female, $11-18$ years & $131 \cdot 36$ & $117.86,144.87$ & 19.87 & $15 \cdot 51,24 \cdot 23$ & $15 \cdot 12$ & $13 \cdot 16,16 \cdot 72$ & $50 \cdot 21$ & $40.47,59.94$ & 38.22 & $34 \cdot 34,41 \cdot 38$ & 39.70 & $34 \cdot 19,45 \cdot 21$ & 30.22 & $29 \cdot 01,31 \cdot 21$ & 9.41 & $6.75,12.07$ & $7 \cdot 16$ & $5.73,8.33$ & $12 \cdot 18$ & $9 \cdot 25,15 \cdot 10$ & 9.27 & $7.85,10 \cdot 42$ \\
\hline Male, $19-64$ years & 177.55 & $165 \cdot 33,189 \cdot 77$ & 40.07 & $34.21,45 \cdot 93$ & 22.57 & $20 \cdot 69,24 \cdot 20$ & 62.46 & $53.53,71 \cdot 40$ & 35.18 & $32.38,37.62$ & 50.05 & $43.67,56.44$ & $28 \cdot 19$ & $26.41,29.74$ & 5.04 & $3.34,6.74$ & 2.84 & $2.02,3.55$ & 19.92 & $16.09,23.75$ & 11.22 & $9 \cdot 73,12$ \\
\hline Female, $19-64$ years & 127.84 & $119 \cdot 63,136.06$ & 26.33 & $22 \cdot 44,30 \cdot 21$ & 20.59 & $18 \cdot 76,22 \cdot 20$ & 38.94 & $33.29,44.59$ & 30.46 & $27.83,32.77$ & 39.41 & $34.79,44 \cdot 02$ & 30.83 & $29 \cdot 09,32 \cdot 36$ & 3.31 & $2 \cdot 16,4 \cdot 46$ & 2.59 & $1 \cdot 81,3 \cdot 28$ & 19.86 & $16 \cdot 76,22 \cdot 95$ & 15.53 & $14.01,16.87$ \\
\hline Male, 65 years + & 151.01 & $133.53,168 \cdot 49$ & 42.22 & $33.65,50.80$ & 27.96 & $25 \cdot 20,30 \cdot 15$ & 52.64 & $40.51,64.77$ & 34.86 & $30.34,38 \cdot 44$ & 29.01 & $19 \cdot 20,38 \cdot 82$ & $19 \cdot 21$ & $14 \cdot 38,23 \cdot 04$ & $1 \cdot 18$ & $0.04,2.41$ & 0.78 & $0.03,1.43$ & 25.95 & $20 \cdot 12,31 \cdot 78$ & 17.18 & $15.07,18$ \\
\hline Female, 65 years + & 103.97 & $94 \cdot 29,113 \cdot 66$ & $26 \cdot 61$ & $20 \cdot 68,32 \cdot 54$ & 25.60 & $21.94,28.63$ & 27.29 & $21 \cdot 29,33 \cdot 30$ & 26.25 & $22 \cdot 58,29 \cdot 30$ & 21.98 & $16 \cdot 59,27 \cdot 36$ & $21 \cdot 14$ & $17.59,24.08$ & 0.80 & $0.09,1.51$ & 0.77 & $0.10,1.33$ & $27 \cdot 29$ & $21 \cdot 66,32 \cdot 92$ & 26.25 & $22 \cdot 97,2$ \\
\hline Total Population & 132.25 & $128.02,136.48$ & $25 \cdot 72$ & $23.88,27.55$ & 19.44 & $18.65,20.19$ & 47.58 & $44 \cdot 68,50 \cdot 49$ & 35.98 & $34.90,36.99$ & 36.00 & $33.88,38.12$ & 27.22 & $26 \cdot 46,27.93$ & 5.28 & $4.61,5.95$ & 3.99 & $3 \cdot 60,4 \cdot 36$ & 17.67 & $16.31,19.04$ & 13.36 & $12.74,13$ \\
\hline
\end{tabular}



from meat across specific categories of alternative. This model is based on a $100 \%$ replacement of meat with the mean nutrient values from each of the separate categories of meat alternative. Compared with the current intake, the substitution of meat, with foods from any of the meat alternative categories, led to a meaningful increase in the projected mean intake of fibre. The greatest projected increase in total fibre was observed in models replacing meat with nut-based products $(10.23 \mathrm{~g} / \mathrm{d})$, followed closely by substitution with vegetable $(8.73 \mathrm{~g} / \mathrm{d})$ or mycoprotein-based products $(8 \cdot 71 \mathrm{~g} / \mathrm{d})$. Substitution with tofubased products had the least impact on projected total fibre intake $(+3 \cdot 14 \mathrm{~g} / \mathrm{d})$.

All product categories were associated with meaningful reductions in projected saturated fat intake. The greatest reduction in saturated fat intake is projected for substitutions with nut-based meat alternatives $(-4.8 \mathrm{~g} / \mathrm{d}, P \leq 0.001)$, whilst the greatest reduction in total projected fat intake was associated with substitution for mycoprotein $(6.12 \mathrm{~g} / \mathrm{d}, P \leq 0 \cdot 001)$. Only the replacements with nut-based and tofu-based meat alternatives did not cause significant reductions in projected total fat intake.

Conversely, projected intakes of protein were lower across each meat alternative category. The greatest projected reductions in total protein intake were observed when substituting in products exclusively from the nut $(-19.79 \mathrm{~g} / \mathrm{d})$, vegetable ($19.33 \mathrm{~g} / \mathrm{d})$ or legume $(-15.43 \mathrm{~g} / \mathrm{d})$ categories. Tofu had the least projected impact on total protein consumption, but it was still associated with a significant reduction in daily intake $(-4.87 \mathrm{~g} /$ d). Replacement of meat with meat alternatives was also associated with an increase in total projected $\mathrm{Na}$ consumption except for the nut-based products $(-124.30 \mathrm{mg} / \mathrm{d})$. Soya-based meat alternatives had the highest $\mathrm{Na}$ content, and replacement with the soya product category raised projected $\mathrm{Na}$ intake by almost $0.5 \mathrm{~g} / \mathrm{d}$.

Regarding micronutrients, the projected intake of vitamin $\mathrm{B}_{12}$ was shown to be statistically significantly reduced in the replacement models with tofu $(-2.02 \mu \mathrm{g} / \mathrm{d} ; P=0.03)$, nut $(-1.88 \mu \mathrm{g} / \mathrm{d}$; $P=0.04)$ and soya $(-1.76 \mu \mathrm{g} / \mathrm{d} ; P=0.05)$, although in each case mean projected intake across the population remained in excess of the RNI.

Total Fe intake was projected to increase in the substitution model with tofu $(+7.63 \mathrm{mg} / \mathrm{d}, P<0 \cdot 001)$. It was not significantly affected by the other meat-replacement scenarios.

In sub-analyses by population group (age and gender), the described influence of these substitution scenarios was replicated in each of the demographics (Supplementary Tables S3-S18).

Model 3: substitution with fortified v. unfortified meat alternatives. In this model, we compared the impact of selecting Fe and $\mathrm{B}_{12}$ fortified $v$. unfortified, meat alternatives, assuming a $100 \%$ replacement of meat. Fortified products accounted for $14 \%$ of the meat alternative products. The projected intake of Fe was significantly higher than current intakes when choosing fortified meat alternatives $(+3.12 \mathrm{mg} / \mathrm{d} ; P<0 \cdot 001)$ and would comfortably attain the UK dietary recommendations (fortified, $16.77 \mathrm{mg} / \mathrm{d} v \cdot 14.8 \mathrm{mg} / \mathrm{d}$ RNI for girls and women aged $11-50$, 
Table 5. Projected differences from current intake for meat alternatives across the total population $(n 1110)$

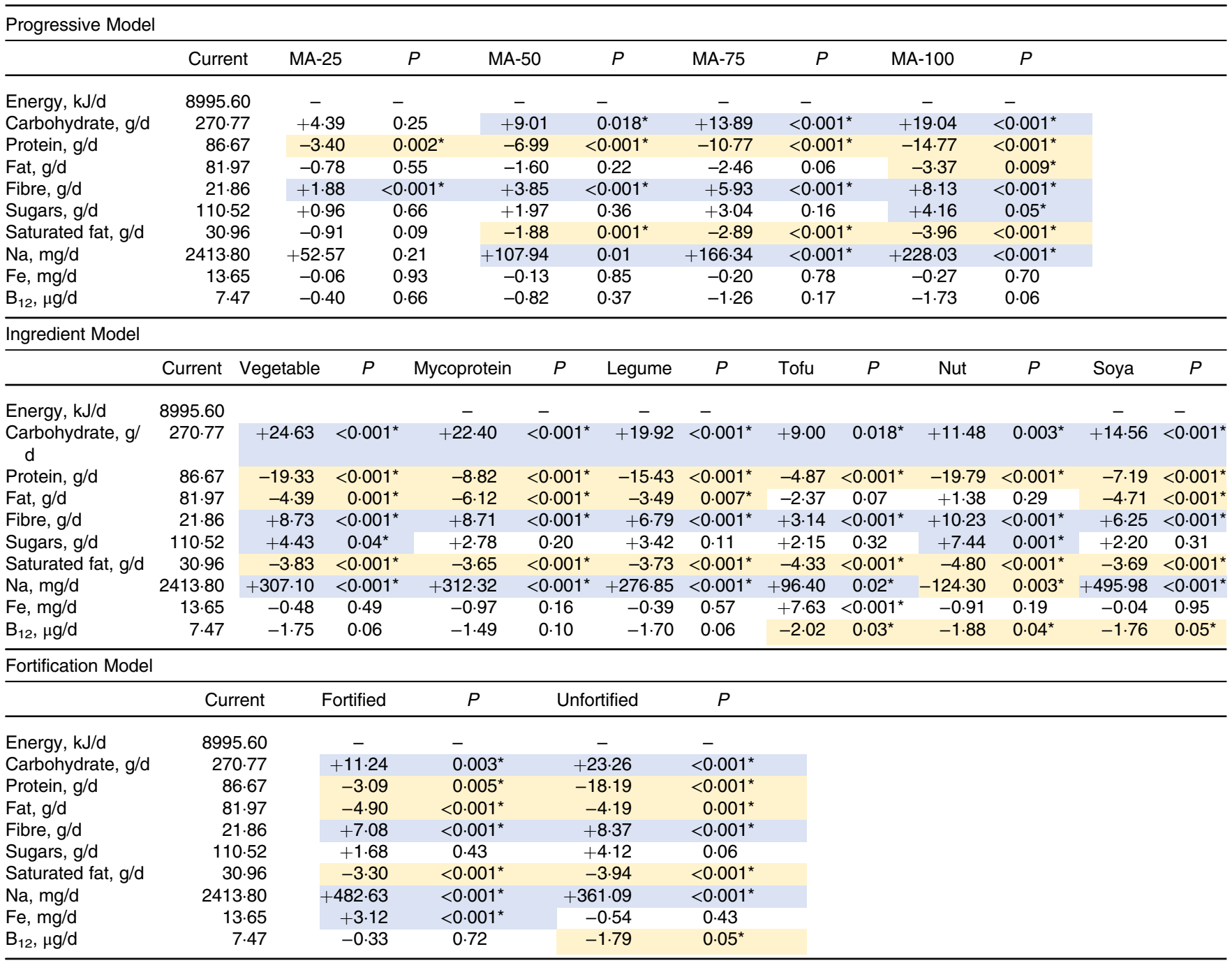

MA-25, replacement model substituting $25 \%$ of self-reported meat intake with composite of meat alternatives; MA- 50 , replacement model substituting $50 \%$ of self-reported meat intake with composite of meat alternatives; MA-75, replacement model substituting $75 \%$ of self-reported meat intake with composite of meat alternatives; MA-100, replacement model substituting $100 \%$ of self-reported meat intake with composite of meat alternatives.

Blue indicates significant increase compared with current. Gold indicates significant decrease compared with current.

*Differences compared using regression models with significance threshold $P<0.05$.

$8.7 \mathrm{mg} / \mathrm{d}$ RNI for remaining population). The projected intake of Fe was not statistically significantly reduced from current levels of intake in the unfortified model.

The projected intake of vitamin $\mathrm{B}_{12}$ was significantly decreased compared with current intakes in the unfortified model $(-1.79 \mu \mathrm{g} / \mathrm{d}, P=0.05)$; however, projected mean intake did not fall below the RNI. In the fortified model, projected intakes of vitamin $\mathrm{B}_{12}$ were not significantly different from current levels of intake.

Interestingly, fortified meat alternatives were associated with a much smaller projected reduction in total protein from current intakes $(-3.09 \mathrm{~g} / \mathrm{d} v .-18.19 \mathrm{~g} / \mathrm{d}$ for the unfortified products $P=0.005)$; however, it was also associated with a greater projected increase in total $\mathrm{Na}$ from current levels of intake $(-482 \mathrm{mg} / \mathrm{d} v .+361 \mathrm{mg} / \mathrm{d}$ for the unfortified products $P<0.001)$
In sub analyses by population group (age and gender), the effect of choosing fortified products described above were replicated across subgroups (Supplementary Tables S3-S18).

\section{Discussion}

We have modelled the projected nutritional impact of a shift in the culinary practices of the meat-eating UK population towards favouring meat alternative products and have identified some important nutritional benefits. Notably, our models predict significant increases in fibre intake and significant decreases in both total fat and saturated fat intake as people switch from meat to meat-alternatives. On the other hand, not all projected impacts on nutrient intake would be described as beneficial; there were notable reductions in total protein and vitamin $\mathrm{B}_{12}$ and projected increases in the intake of $\mathrm{Na}$ and of sugars. 
The UK dietary guidelines recommend limiting fat to no more than $35 \%$ of total energy. This target is generally met by the UK population, but further displacement of fat with fibre may have the potential to reduce total energy intake with consequences for body composition. We observed significant reductions in projected total fat intake across our model scenarios, with the exception of the nut and tofu-based alternatives. The greatest projected reduction in fat was associated with mycoprotein; if we assumed no dietary adjustment for total energy, daily replacement of meat with mycoprotein might be projected to reduce fat intake by the equivalent of $225.94 \mathrm{~kJ} / \mathrm{d}$, a level of reduction more than sufficient to offset weight gain ${ }^{(39)}$.

The UK guidelines set an upper limit of $11 \%$ of total energy for saturated fat due to its association with $\mathrm{CVD}^{(33,37)}$. Actual intakes of saturated fat remain above this threshold despite long-running public health initiatives. We observed that a $100 \%$ replacement of meat with meat alternatives would take total projected saturated fat intake very close to the $11 \%$ of food energy target. This observation was consistent across the categories of meat alternative, but with the greatest projected reductions in saturated fat being observed with the nut-based and tofu-based products categories. Nut- and tofu-based meat alternatives may be of further interest as the projected displacement of saturated fat was with MUFA more so than carbohydrate ${ }^{(40-42)}$. Swapping SFA, for MUFA and PUFA, is considered optimal for heart health ${ }^{(43)}$.

The RNI for protein is greatly exceeded by most UK consumers pursuing an omnivorous, energy balanced diet. However, in our models, the projected reduction in total protein intake from a $100 \%$ replacement of meat was equivalent to almost $20 \mathrm{~g} / \mathrm{d}$ if alternative foods were drawn exclusively from the vegetableor nut-based product categories. These losses have the potential to compromise protein status in athletes, in the very young, in the aged and in certain disease states where requirements may be above the RNI. Where protein intake is a concern, we would recommend choosing products from the higher protein, tofu-, soyaand mycoprotein-based meat-alternative categories.

Dietary patterns high in fibre are associated with improved satiety, reduced risk of obesity, improved metabolic health and reduced risk of diverticular disease, cancer, cardiovascular disease and hypertension ${ }^{(44,45)}$; the UK dietary guidelines recommend that adults consume upwards of $30 \mathrm{~g}$ of AOAC fibre per day ${ }^{(33,37)}$. Despite consistent public health campaigns over many years, dietary fibre consumption amongst the UK public remains significantly below this recommendation ${ }^{(46)}$. Using a refined NDNS cohort, incorporating meat eaters only, we noted that current mean fibre intake is $21.86 \mathrm{~g} / \mathrm{d}$. In our models, under every meat-replacement scenario, projected fibre intake was shown to increase significantly compared with current intake for the total population. Importantly, the models showing a $100 \%$ replacement of meat with meat alternatives would increase the mean projected fibre intake, at a population level, to $30 \mathrm{~g} / \mathrm{d}$ (Table 4).

We noted considerable differences in fibre content between, and within, our meat alternative product categories, with the highest projected increase in fibre intake being associated with vegetable, nut and mycoprotein-based products. Not all fibre elicits the same physiological benefits ${ }^{(47)}$, and therefore it is important to note that fibre composition, and functional activity, is better described for soya-based ${ }^{(48)}$ and mycoprotein-based ${ }^{(49)}$ meat alternatives than it is the for the nut, vegetable and tofu categories of product.

Non-milk extrinsic sugar intake in the UK remains well above current guidelines which suggest limiting intake to no higher than $5 \%$ of total energy intake. In our meat eating NDNS cohort, sugar intake was closer to $20 \%$ of total energy intake. A high intake of sugars may be associated with obesity and poor dental health outcomes ${ }^{(50)}$; therefore, any intervention that raises sugar consumption must be viewed as problematic. We noted particularly high sugar levels in the nut-based and vegetable-based product categories and in the $100 \%$ meat displacement scenarios involving these two product categories, projected sugar intake rose to almost $22 \%$ of energy intake.

Due to its associations with hypertension, kidney disease and some cancers, dietary Na reduction has been the goal of a multipronged and effective public health campaign over the past two decades $^{(51)}$. Intakes in the UK have decreased by clinically meaningful levels in recent years; in the meat eating NDNS cohort used in this analysis, mean $\mathrm{Na}$ intake was reported as being very close to the current guidelines. Unfortunately, many of the meat alternative products were found to be high in $\mathrm{Na}$, and in the $100 \%$ meat-replacement model, total projected $\mathrm{Na}$ intake was increased by $0.23 \mathrm{~g}$. As with the other nutrients, there was considerable variation in the Na content of foods from within and across alternative product categories; of note, soya-based meat alternatives were found to be particularly high in $\mathrm{Na}$, and a scenario with $100 \%$ meat displacement for soya-based products was projected to raise $\mathrm{Na}$ intake by almost $0.5 \mathrm{~g} / \mathrm{d}$. We caution that our displacement models cannot fully account for salt added at the table or in the preparation of meat dishes.

Fe intake amongst girls and women in the UK is marginal with the mean intakes for both girls aged 11 to 18 years, and women aged 19 to 64 years below the RNI $(56 \%$ and $76 \%$ of the RNI respectively), and further, $49 \%$ of girls aged 11 to 18 years and $25 \%$ of women aged 19 to 64 years have Fe intakes below the lower $\mathrm{RNI}^{(52)}$. There is also evidence of both Fe-deficiency anaemia (as indicated by low haemoglobin levels) and low Fe stores (plasma ferritin) in $9 \%$ of older girls, $5 \%$ of adult women and $2 \%$ of older women ${ }^{(52)}$. Replacing meat with meat alternative products did not significantly reduce projected total $\mathrm{Fe}$ intake; in fact, replacement with either tofu or with Fe-fortified meat alternatives was associated with a significant increase in Fe intake. Therefore, if meat alternatives are integrated into the dietary habits of the UK population, fortification of these foods with Fe could facilitate the widespread attainment of RNI.

In the UK population, vitamin $\mathrm{B}_{12}$ deficiency is rarely due to poor dietary intake, but it can be induced by a poorly managed vegan diet ${ }^{(54)}$, and thus $B_{12}$ intake should be considered in any public health approaches in reducing animal product intake. In our model scenarios, we observed slight reductions in $\mathrm{B}_{12}$, approaching statistical significance with a total replacement of meat, and particularly evident when the replacement products were from the nut and tofu product categories. This reduction in projected $\mathrm{B}_{12}$ intake was largely offset in the model with fortified alternatives. In our models, the projected intakes of $\mathrm{B}_{12}$ following meat replacement remained significantly above the RNI, and therefore might be deemed of limited public health 
Table 6. Implications and recommendations

\begin{tabular}{|c|c|}
\hline i/Food consumers & $\begin{array}{l}\text { Consumers choosing to reduce their meat intake should understand that meat alternative products are a culinary replacement for } \\
\text { meat, which differ in their nutritional profile. With the exception of tofu and mycoprotein, we caution that few meat alternative prod- } \\
\text { ucts have been well evaluated for their physiological effects in the consumer. We would therefore strongly recommend selecting } \\
\text { meat alternatives based on the level of nutritional characterisation and the availability of high-quality evidence about their health- } \\
\text { fulness. It is also important to consider the wider balance of the diet to ensure that the intake of nutrients found in meat is not } \\
\text { compromised when reducing the intake. }\end{array}$ \\
\hline ii/Producers & $\begin{array}{l}\text { Producers of meat alternatives should be encouraged to focus on Na reduction, deeper nutritional characterisation, and where fea- } \\
\text { sible, investigations evidencing the likely health benefits of their products. Given their market, voluntary product fortification with } \\
\mathrm{Fe} \text { and } \mathrm{B}_{12} \text { might also be considered. }\end{array}$ \\
\hline
\end{tabular}

Table 7. Nutritional comparisons across meat substitute product category

\begin{tabular}{|c|c|c|c|c|c|c|c|c|c|}
\hline Ingredient model & Carbohydrate $(\mathrm{g} / \mathrm{d})$ & Protein $(\mathrm{g} / \mathrm{d})$ & Fat $(g / d)$ & Fibre $(g / d)$ & Sugars $(g / d)$ & Saturated fat $(\mathrm{g} / \mathrm{d})$ & $\mathrm{Na}(\mathrm{mg} / \mathrm{d})$ & $\mathrm{Fe}(\mathrm{mg} / \mathrm{d})$ & $B_{12}(\mu \mathrm{g} / \mathrm{d})$ \\
\hline Vegetable & $\uparrow$ & $\downarrow$ & $\downarrow$ & $\uparrow$ & $\uparrow$ & $\downarrow$ & $\uparrow$ & - & - \\
\hline Mycoprotein & $\uparrow$ & $\downarrow$ & $\downarrow$ & $\uparrow$ & + & $\downarrow$ & $\uparrow$ & - & - \\
\hline Legume & $\uparrow$ & $\downarrow$ & $\downarrow$ & $\uparrow$ & + & $\downarrow$ & $\uparrow$ & - & - \\
\hline Tofu & $\uparrow$ & $\downarrow$ & - & $\uparrow$ & + & $\downarrow$ & $\uparrow$ & $\uparrow$ & $\downarrow$ \\
\hline Nut & $\uparrow$ & $\downarrow$ & + & $\uparrow$ & $\uparrow$ & $\downarrow$ & $\downarrow$ & - & $\downarrow$ \\
\hline Soya & $\uparrow$ & $\downarrow$ & $\downarrow$ & $\uparrow$ & + & $\downarrow$ & $\uparrow$ & - & $\downarrow$ \\
\hline
\end{tabular}

+ , Non-significant increase compared with current intake; -, non-significant decrease from current intake. $\uparrow$, significant increase compared with current intake; $\downarrow$, significant decrease from current intake.

consequence. However, we caution that we did not remove milk, eggs, and other dairy products from our models, and we would expect further reductions in $\mathrm{B}_{12}$ under those scenarios. For individuals pursuing a vegan diet, it remains sensible to choose fortified products and to consider $\mathrm{B}_{12}$ supplementation.

To our knowledge, this is the first study to consider the projected impact of this important, relatively novel, food category at a population level in the UK. The strengths of this work are that we leverage the National Dietary Nutrition Survey data set; this is a very well developed and informative record of food habits in the UK. We have also captured a broad picture of the nutritional quality of meat alternative products from within the UK market in 2020 .

The limitations of this study are that we are reliant upon selfreported dietary intake data from the NDNS. The 4-day food record collection tool used in the NDNS can change habitual diet, and the heavy respondent work load may precipitate socio-economic representation bias in the cohort. We have also made subjective decisions in approaching the analysis; most notably, we chose to keep the energy content of the substitution models constant by increasing the nutritional intake uniformly across the data set after the substitution. The energy adjustment approach is consisted of previous literature evaluating the impacts of dietary substitutions ${ }^{(55,56)}$. However, whilst we assume that individuals will maintain energy balance in a meat-replacement scenario, we cannot be certain which foods they are likely to adjust their intake of, and this could affect the overall projected nutritional intake. We were further limited by the depth of nutritional data and relatively poor characterisation of many of the meat alternatives. Across the product categories, mycoprotein and soya-based products were generally well characterised, but there was a paucity of B vitamin and mineral data for many of the product categories, which has been noted previously ${ }^{(35)}$. This meant that we were limited in the nutrients we could assess. Data pertaining to the nutritional profile of meat alternatives within the McCance and Widdowson data set are scarce, and there is a need for greater analytical work to be done to update and formulate databases for these foods. If meat alternatives are to be regularly consumed as part of the diet in place of meat, publication of a more comprehensive characterisation of their nutritional composition would be welcome.

There are implications arising from this work for consumers, producers and food policy makers (Table 6). For food consumers, it is clear there are many nutritious approaches to reducing meat intake using meat alternatives. We note the variable density of different nutrients across meat substitute categories as summarised in Table 7, none of these substitutes fully replicates the nutritional composition of meat. If choosing to use meat alternatives, we therefore recommend using a variety of products from across the meat substitute categories. We also recommend choosing products high in protein and fibre and low in saturated fat and sugar; where possible, we would advise choosing products that are good sources of Fe and vitamin $\mathrm{B}_{12}$. Producers of meat alternatives could better serve consumers with stronger nutritional labelling and by focussing on $\mathrm{Na}$ and sugar reduction. Producers might also consider voluntary fortification with Fe and $\mathrm{B}_{12}$. Food policy makers might consider regulation around fortification, marketing and labelling to better guide consumer choice. 


\section{Conclusion}

Reducing meat consumption will be a focus of public health and ecological food policy for the foreseeable future. It is therefore anticipated that meat alternatives will play an increasingly prominent role in the UK food plate. Consumer confidence in the new and dynamic meat alternative market will be an important aspect in facilitating the level of dietary change required to protect planetary and consumer health. Going forward, periodic monitoring of the nutritional quality and healthfulness of meat alternatives will be necessary to ensure that these foods compare well on a nutritional playing field and that nutrient analytical databases are kept up to date with this information. This will then aid better quality research and the compilation of more accurate recommendations that relate to public health policy.

\section{Acknowledgement}

The authors would like to thank Dr Emma Derbyshire for kindly providing a constructive proof reading of this manuscript.

This research received no specific grant from any funding agency, commercial or not-for-profit sectors.

D.N.F is supported via a PhD studentship part funded by Marlow Foods Ltd. D.M.C and J.M have received research funding from Marlow Foods Ltd. This work has been conducted independently of Marlow foods and the authors have no financial or other vested interest in the outcome of the work.

The authors' responsibilities were as follows: D.N.F was responsible for study conception, data collection, analyses and writing the manuscript. D.M.C aided in study conception and writing the manuscript. D.U aided in data collection, and J. M. contributed to revising the manuscript.

\section{Supplementary material}

For supplementary material accompanying this paper visit https://doi.org/10.1017/S0007114521002750

\section{References}

1. Xu T (2020) Analysis on the meat consumption, dietary transformation and cultured meat. IOP Conf Ser 512, 012079.

2. Vermeulen SJ, Campbell BM, Ingram JSI (2012) Climate change and food systems. Annu Rev Environ Resour 37, 195-222.

3. Diaz RJ \& Rosenberg R (2008) Spreading dead zones and consequences for marine ecosystems. Science 321, 926-929.

4. Ramankutty N, Evan AT, Monfreda C, et al. (2008) Farming the planet: 1. Geographic distribution of global agricultural lands in the year 2000. Glob Biogeochem Cycles 22, GB1003.

5. Shiklomanov I \& Rodda J (2004) World Water Resources at the Beginning of the Twenty-First Century. Cambridge University Press, pp. 13.

6. Micha R, Michas G, Mozaffarian D (2012) Unprocessed red and processed meats and risk of coronary artery disease and type 2 diabetes - an updated review of the evidence. Curr Atheroscler Rep 14, 515-524.

7. Pan A, Sun Q, Bernstein AM, et al. (2013) Changes in red meat consumption and subsequent risk of type 2 diabetes mellitus: three cohorts of US men and women. JAMA Intern Med $\mathbf{1 7 3}$, $1328-1335$.
8. Zhong VW, Van Horn L, Greenland P, et al. (2020) Associations of processed meat, unprocessed red meat, poultry, or fish intake with incident cardiovascular disease and all-cause mortality. JAMA Intern Med. 180(4), 503-512.

9. Alexander DD, Mink PJ, Cushing CA, et al. (2010) A review and meta-analysis of prospective studies of red and processed meat intake and prostate cancer. Nutr J 9, 50.

10. Bernstein AM, Song M, Zhang X, et al. (2015) Processed and unprocessed red meat and risk of colorectal cancer: analysis by tumor location and modification by time. PLOS ONE 10, e0135959.

11. Bouvard V, Loomis D, Guyton KZ, et al. (2015) Carcinogenicity of consumption of red and processed meat. Lancet Oncol. 16, 1599-600.

12. Cho E, Chen WY, Hunter DJ, et al. (2006) Red meat intake and risk of breast cancer among premenopausal women. Arch Intern Med 166, 2253-2259.

13. Cross AJ, Leitzmann MF, Gail MH, et al. (2007) A prospective study of red and processed meat intake in relation to cancer risk. PLoS Med 4, e325.

14. Genkinger JM \& Koushik A (2007) Meat consumption and cancer risk. PLoS Med 4, e345.

15. Inoue-Choi M, Sinha R, Gierach GL, et al. (2016) Red and processed meat, nitrite, and heme iron intakes and postmenopausal breast cancer risk in the NIH-AARP Diet and Health Study. Int J Cancer 138, 1609-18.

16. Key TJ, Bradbury KE \& Murphy N (2019) Diet and colorectal cancer in UK Biobank: a prospective study. Int $J$ Epidemiol 49(1), 246-258.

17. Sanchez-Sabate R \& Sabaté J (2019) Consumer attitudes towards environmental concerns of meat consumption: a systematic review. Int J Environ Res Public Health 16, 1220.

18. Kumar P, Chatli MK, Mehta N, et al. (2017) Meat analogues: health promising sustainable meat substitutes. Crit Rev Food Sci Nutr 57, 923-932.

19. Apostolidis C \& McLeay F (2016) Should we stop meating like this? Reducing meat consumption through substitution. Food Policy 65, 74-89.

20. Dagevos H \& Voordouw J (2013) Sustainability and meat consumption: is reduction realistic? Sustainability 9, 60-69.

21. Schösler H, Boer Jd, Boersema JJ (2012) Can we cut out the meat of the dish? Constructing consumer-oriented pathways towards meat substitution. Appetite 58, 39-47.

22. Hu FB, Otis BO, McCarthy G (2019) Can plant-based meat alternatives be part of a healthy and sustainable diet? JAMA 322, $1547-1548$.

23. Hemler EC \& Hu FB (2019) Plant-based diets for cardiovascular disease prevention: all plant foods are not created equal. Curr Atheroscler Rep. 21, 18.

24. NatCen Social Research; MRC Elsie Widdowson Laboratory, inventorNational Diet and Nutrition Survey Years 1-9, 2008/ 09-2016/172019.

25. Bates B, Cox L, Nicholson S, et al. (2016) National Diet, Nutrition Survey results from years 5, 6 (combined) of the Rolling Programme (2012/2013-2013/2014). London: Public Health England.

26. Bates B, Lennox A, Prentice A, et al. (2014) National diet, nutrition survey: Results from years 1, 2, 3, 4 (combined) of the rolling programme (2008/2009-2011/2012): A survey carried out on behalf of public health England, the food standards agency: Public Health England.

27. Roberts C, Steer T, Maplethorpe N, et al. (2018) National Diet, nutrition survey: results from years 7,8 (combined) of the rolling Programme (2014/2015-2015/2016).

28. Macdiarmid J \& Blundell J (1998) Assessing dietary intake: who, what and why of under-reporting. Nutr Res Rev 11, 231-253. 
29. Poslusna K, Ruprich J, de Vries JHM, et al. (2009) Misreporting of energy and micronutrient intake estimated by food records and 24 hour recalls, control and adjustment methods in practice. Br J Nutr 101, S73-S85.

30. McCance RA, Widdowson EM (2014) McCance and Widdowson's the Composition of Foods. Royal Society of Chemistry.

31. Mintel (2019) Exectuive Summary Meat-Free Foods - UK November 2019. Mintel Group Ltd.

32. Department of Health (1991) Dietary Reference Values for Food Energy and Nutrients for the United Kingdom: Report of the Panel on Dietary Reference Values of the Committee on Medical Aspects of Food Policy: Reports of Health and Social Subjects; $41,1-210$.

33. Public Health England (2016) Government Recommendations for Food Energy and Nutrients for Males and Females Aged 1-18 Years and 19+ Years. Available online: https://www.gov.uk/ government/uploads/system/uploads/attachment_data/file/54 7050/government_dietary_recommendations.pdf (accessed on 12 October 2020)

34. Gibson R, Eriksen R, Chambers E, et al. (2019) Intakes and food sources of dietary fibre and their associations with measures of body composition and inflammation in UK adults: crosssectional analysis of the airwave health monitoring study. Nutrients 11, 1839.

35. Curtain F \& Grafenauer S (2019) Plant-based meat substitutes in the flexitarian age: an audit of products on supermarket shelves. Nutrients $\mathbf{1 1}, 11$.

36. Craig WJ (2009) Health effects of vegan diets. Am J Clin Nutr 89, $1627 \mathrm{~S}-1633 \mathrm{~S}$

37. Scientific Advisory Committee on Nutrition. Dietary Reference Values for Energy. In: Scientific Advisory Committee on Nutrition, editor. London2011.

38. R Core Team (2020) $R$ : A language and environment for statistical computing. R Foundation for Statistical Computing.

39. Sacks FM, Bray GA, Carey VJ, et al. (2009) Comparison of weight-loss diets with different compositions of fat, protein, and carbohydrates. $N$ Engl J Med 360, 859-873.

40. Rizzo G \& Baroni L (2018) Soy foods and their role in vegetarian diets. Nutrients 10, 43.

41. Ros E (2010) Health benefits of nut consumption. Nutrients $\mathbf{2}$, 652-682.

42. Ros E \& Mataix J (2006) Fatty acid composition of nuts-implications for cardiovascular health. Br J Nutr 96 (Suppl. 2), S29-S35.

43. Nettleton JA, Brouwer IA, Geleijnse JM, et al. (2017) Saturated fat consumption and risk of coronary heart disease and ischemic stroke: a science update. Ann Nutr Metab. 70, 26-33.
44. Slavin J (2013) Fiber and prebiotics: mechanisms and health benefits. Nutrients 5, 1417-1435.

45. Veronese N, Solmi M, Caruso MG, et al. (2018) Dietary fiber and health outcomes: an umbrella review of systematic reviews and meta-analyses. Am J Clin Nutr 107, 436-44.

46. Stephen AM, Champ MMJ, Cloran SJ, et al. (2017) Dietary fibre in Europe: current state of knowledge on definitions, sources, recommendations, intakes and relationships to health. Nutr Res Rev 30, 149-190.

47. Gibson GR, Hutkins R, Sanders ME, et al. (2017) Expert consensus document: The International Scientific Association for Probiotics and Prebiotics (ISAPP) consensus statement on the definition and scope of prebiotics. Nat Rev Gastroenterol Hepatol. 14, 491-502.

48. Yang L, Zhao Y, Huang J, et al. (2020) Insoluble dietary fiber from soy hulls regulates the gut microbiota in vitro and increases the abundance of bifidobacteriales and lactobacillales. J Food Sci Technol. 57, 152-162.

49. Harris HC, Edwards CA, Morrison DJ (2019) Short chain fatty acid production from mycoprotein and mycoprotein fibre in an in vitro fermentation model. Nutrients $\mathbf{1 1}$.

50. Campbell R, Tasevska N, Jackson KG, et al. (2017) Association between urinary biomarkers of total sugars intake and measures of obesity in a cross-sectional study. PLOS ONE. 12, e0179508.

51. Mente A, O'Donnell M, Rangarajan S, et al. (2018) Urinary sodium excretion, blood pressure, cardiovascular disease, and mortality: a community-level prospective epidemiological cohort study. Lancet. 392, 496-506.

52. Public Health England. National Diet and Nutrition Survey (NDNS): results from years 9 to 11 (combined) - statistical summary. Published 11 December 2020.

53. Lopez A, Cacoub P, Macdougall IC, et al. (2016) Iron deficiency anaemia. The Lancet. 387, 907-916.

54. Lederer A-K, Hannibal L, Hettich M, et al. (2019) Vitamin B12 status upon short-term intervention with a vegan diet-a randomized controlled trial in healthy participants. Nutrients $\mathbf{1 1}$, 2815.

55. Mertens E, Biesbroek S, Dofková M, et al. (2020) Potential impact of meat replacers on nutrient quality and greenhouse gas emissions of diets in four European countries. Sustainability 12, 6838.

56. Springmann M, Wiebe K, Mason-D'Croz D, et al. (2018) Health and nutritional aspects of sustainable diet strategies and their association with environmental impacts: a global modelling analysis with country-level detail. Lancet Planetary Health $\mathbf{2}$, e451-e61. 